\title{
Pensar la educación, pensar el Brasil-1822/2022: una estrategia de disputa por los sentidos de la educación ${ }^{1}$
}

\section{Luciano Mendes de Faria Filho}

Facultad de Educación,

Universidad Federal de Minas Gerais, Brasil

Cuando acepté impartir esta conferencia en el XV Encuentro Internacional de Historia de la Educación jamás imaginé que la sociedad brasileña cometería una estupidez tan grande como en las últimas elecciones y que daría un paso atrás en el terreno ganado por la conquista de una mayor independencia, tanto en términos individuales como sociales. ¡En verdad no imaginaba que estábamos tan cerca del abismo y, mucho menos, que escogeríamos arrojarnos a él! Por esta razón mi conferencia está fuertemente influida por los últimos acontecimientos en Brasil, y les ofrezco disculpas por eso, pero no me fue posible proceder de otra forma.

Creo que las elecciones brasileñas en las cuales una buena parte de nuestros conciudadanos escogieron a un capitán fascista — que ha sido expulsado del ejército brasileño por malos servicios - para ocupar el puesto más alto de nuestra República es un buen motivo para que los demócratas de América Latina y de todo el mundo quedemos preocupados. Pero es también un motivo para que la comunidad de historia de la educación brasileña y latinoamericana se movilice tanto para colaborar en el análisis y la comprensión de este fenómeno como para ayudarnos a salir del abismo al que nosotros mismos nos hemos arrojado.

Las elecciones brasileñas no han trascurrido en un ambiente normal de disputa democrática, y esto también trae cuestionamientos para nosotros como ciudadanos y como historiadores de la educación. Por lo menos cuatro elementos hicieron la diferencia en la disputa por el ejecutivo y los escaños legislativos. En primer lugar, actuó con gran fuerza un odio contra el Partido de los Trabajadores, contra los errores del mismo, ciertamente, pero creo que es, básicamente, un odio contra los aciertos del partido, que logró combatir la pobreza y las desigualdades brasileñas y, sobre todo, transformar en políticas una serie de

\footnotetext{
${ }^{1}$ Esta reseña fue presentada como conferencia de cierre del XV Encuentro Internacional de Historia de la Educación "Movimientos, desigualdades y reformas educativas en el tiempo" realizado en la ciudad de Pachuca del 8 al 10 de noviembre de 2018. ${ }^{2}$ Me refiero a Bazant (2002), Bustamante (2014) y Escalante (2014). Para Oaxaca ya hay capítulos, artículos y tesis de investigación pero aún no libros, por ejemplo, Traffano (2007 y 2016) y Martínez (2014). Véase también la revisión de Martín y Escalante (2017) sobre la bibliografía disponible.
} 
reivindicaciones del movimiento de los negros, de las mujeres y de la comunidad LCBTQI en Brasil. Desde este punto de vista las elecciones brasileñas de 2018 fueron la coronación del golpe parlamentario de 2016.

El segundo elemento que ha alterado la normalidad de las elecciones en Brasil es la fuerte actuación de los poderes y de las instituciones al crear las condiciones para que el candidato de la extrema derecha lograra vencer. Una parte de esta actuación — la más importante, creo yo - fue el encarcelamiento de Lula. Pero también el Poder Judicial colaboró al divulgar informes sin fundamento para perjudicar al candidato Fernando Hadad a pocos días de las elecciones, además de la negativa del tribunal electoral a investigar la industria de fake news, entre otros ejemplos.

El tercer aspecto es la propia industria de fake news que asoló al país durante las semanas anteriores a las elecciones. La acción fue tan intensa y violenta que tengo muy claro que nuestras elecciones fueron un gran fraude a la democracia. Es imposible pensar desde nuestro concepto de democracia, incluso en términos de una democracia representativa liberal, en una elección en la cual las persona son consciente y masivamente desinformadas con la fabricación a escala industrial de fake news que explotan los más profundos temores de la población; una elección en estas condiciones no es y ni puede ser democrática. Pero lo más alarmante de estas elecciones en Brasil es la adhesión fascista de un gran sector de la población brasileña. Es cierto que no todas las personas que votaron por Bolsonaro son fascistas; sin embargo, muchos de los que eligieron el fascismo optaron conscientemente por una dictadura, por la tortura como política oficial, por la autorización para que la policía pueda matar, por la acción del Estado contra los derechos humanos, en fin..., optaron por la barbarie contra la civilización e hicieron una elección muy poco razonable teniendo en cuenta sus propios intereses y sus propios derechos.

No hay otra motivación para que en estos días haya recordado muchas veces en el "ángel de la historia" de Walter Benjamin (1985: 222-232). En la perspectiva de Benjamin, el ángel de Klee se encuentra de espaldas al futuro y, con las alas abiertas es empujado por el viento, mientras mira asombrado el pasado. Es una muy creativa crítica a la idea de progreso y al mismo tiempo a una concepción del pasado como un tiempo muerto que sólo podemos contemplar. ¡El pasado no está muerto, así como el futuro no está asegurado! Las fuerzas de la barbarie que actúan en el presente nos imponen hacer la historia en su doble sentido: como una lucha contra el futuro catastrófico que se anuncia y contra el pasado único que lo autoriza. El presente, el pasado y este en que vivimos es un tiempo saturado de "ahoras". Por eso se hace necesario aprovechar esos "ahoras" para disputar los sentidos de las cosas, entre ellas, los sentidos de la educación.

Nosotros tenemos en Brasil un proyecto que llamamos "Pensar la educación, pensar el Brasil-1822/2022" a través del cual, hace más de una década, buscamos movilizar a la co- 
munidad académica brasileña hacia la disputa de los sentidos de la educación en el espacio público. Para ello organizamos un programa de radio, un semanario, una revista de divulgación, una colección de libros, un ciclo de conferencias anuales y muchas otras actividades junto con los maestros (de educación básica). Nuestra idea ha sido aprovechar el momento de celebrar el bicentenario de la independencia brasileña para generar una profunda discusión del lugar de la educación en nuestra historia. ${ }^{2}$

Para muchos de nuestros colegas el proyecto debería llamarse "Pensar el Brasil, pensar la educación", pues el Brasil es la temática mayor y, por tanto, la que engloba la educación. Pero nuestra perspectiva es justamente que a través de la educación, así como de la política, la economía, las artes o la salud es posible, metodológicamente, comprender el Brasil. Es, pues, una mirada que no considera que la historia política o la historia económica sean las verdaderas historias y que las otras son miradas menos potentes para pensar y entender el país. Desde este punto de vista, una mirada hacia la historia de la educación de Brasil demuestra que en nuestro país el sistema escolar no precede al Estado; es decir, la escuela fue en verdad una de las formas de construcción del Estado Nacional (ver Hamilton, 2006: 95-110) , articulando con su regularidad y capilaridad el gobierno de la población. O sea, en nuestro país la debilidad o la potencia de la educación en su forma escolarizada siempre ha sido una demostración de la debilidad o la potencia del Estado en su relación con los distintos sectores de la población.

Veamos dos ejemplos de lo anterior. En Brasil el Estado, en sus diversos niveles de gobierno, siempre fue muy pródigo en construir escuelas de experimentación, siempre muy buenas, con las mejores condiciones laborales y salariales, con los mejores profesores, localizadas en buenos sitios, escuelas a las que usualmente asisten los sectores más adinerados de la población (Caldas, 2012). Pero han sido pocas las unidades de demostración cuyos resultados jamás se han extendido a las demás escuelas justamente porque las condiciones materiales y sociales no lo permitirían. Pero, durante mucho tiempo, incluso hoy, la idea de crear una escuela de experimentación ha legitimado la construcción de escuelas públicas de alta calidad para un pequeño y privilegiado grupo de estudiantes oriundos de los estratos más ricos de la sociedad.

Del mismo modo, se puede analizar la construcción de una red de universidades públicas en el país (Cunha, 1989). Desde el nacimiento de nuestra nación, primero el Imperio después la República, el gobierno centralizó la organización y el mantenimiento de las instituciones

\footnotetext{
${ }^{2}$ Hay un sitio en la red internet (www.pensaraeducação.com.br) donde se puede obtener información sobre el proyecto y sus innumerables acciones de divulgación de conocimiento y de formación de las maestras de la educación básica brasileña. Quiero destacar, especialmente, la Revista Brasileira de Educação Básica (RBEB) cuyo objetivo es reconocer y fortalecer la autoría de las maestras y los maestros de la educación básica, además de que recibe y publica textos en español.
} 
de enseñanza superior para la educación de las élites dirigentes; mientras dejaba que las provincias y después, los estados y las municipalidades se hicieran responsables por la educación secundaria y primaria, o sea, de la población más pobre, de los negros, de las mujeres y de los obreros de manera general. Siempre fue así, sin cuestionamientos: las universidades públicas para los más ricos mientras que los pobres, cuando llegaban al nivel superior, tenían que estudiar en las instituciones privadas. Pero ahora, justamente ahora, cuando los negros, los indígenas, los pobres, incluso las mujeres negras y pobres, logran llegar a la universidad pública hay un discurso de que ésta es muy costosa para el erario y que, por tanto, debe pagarla los estudiantes y sus familias.

Los ejemplos anteriores son la muestra de que la excelencia de la escuela es una forma de dar visibilidad al poder del Estado para beneficiar a la población más rica. Del mismo modo, las malas condiciones de trabajo, las pésimas condiciones materiales de las escuelas y el bajo salario de las maestras de nivel primaria que se ofrece a la mayoría de la población es una demostración cotidiana y secular del desprecio de los gobernantes por la educación escolar de los más pobres. Pero a estos últimos no se les olvidó la violencia oficial, de la policía, de los juzgados y de las élites locales, con sus fuerzas particulares de represión, que fueron las prácticas educativas en la vida cotidiana para los trabajadores, para los negros y para los indígenas.

A ese respeto, el pensamiento social brasileño de los años treinta y cuarenta del siglo pasado creó el mito de la democracia racial y la cordialidad de los brasileños. Por caminos diferentes la tradición iniciada por Gilberto Freyre y Sérgio Buarque, de Holanda, en aquel momento logró hacer historia entre nosotros. Y ese imaginario aun cuando es contrariado cotidianamente por los hechos como la matanza de jóvenes negros o el exterminio de la población indígena, permanece en nosotros como una "mentalidad", o sea, como disposición mental y de acción, profundamente impregnada en las personas e institucionalizada.

Por eso no es de extrañar que en el país más violento del mundo —en donde la policía mata más gente pobre y negra que en cualquier otra parte-, la población está de acuerdo con que una de las formas de combatir la violencia es que la policía esté autorizada a matar en servicio y que esas muertes no se investiguen oficialmente. Del mismo modo, este imaginario nos ayuda a entender por qué la población está contra las políticas de acciones afirmativas por entenderlas como una fórmula del Partido de los Trabajadores que promueve los conflictos raciales en el Brasil al considerarlas como una ayuda a los estudiantes o a los "malvivientes" que no quieren estudiar ni trabajar con ahínco.

Además del privilegio concedido como política pública a un sector de la población en contra del reconocimiento de los derechos de todos, de la violencia como estrategia educativa básica contra los "otros" - pobres, negros, mujeres, indígenas, gays, lesbianas ...- y del imaginario de una sociedad poco conflictiva, otro aspecto que debemos tener en mente en 
la historia de la educación brasileña es una presencia muy fuerte, extensiva y ostentosa de la religión católica como religión oficial hasta finales del siglo XIX, y más o menos oficial hasta hoy. Hasta hace muy poco tiempo nuestras escuelas no dejaron de ser católicas y hoy, cuando dejan de serlo, es para poner en práctica otras religiones cristianas. Lo mismo ocurre con nuestra cultura política. Por los medios más diversos nuestros dirigentes políticos siempre urden maneras de mostrar, en el ejercicio mismo de sus funciones, que nuestras instituciones públicas son cristianas: es el preámbulo de nuestra Constitución que se refiere al nombre de dios, es la imagen religiosa en la sala del tribunal, es el calendario católico que se impone al mundo civil, por citar sólo algunos ejemplos.

Esa representación cristiana del mundo, con la imágenes y demás prácticas que le dan sustento y permanencia, logró construir en el espacio público, incluso en la escuela, la certeza de que un buen ciudadano o -como defienden la extrema derecha y sus aliados en Brasil- el "ciudadano de bien" es necesariamente cristiano, fuera de eso todo es suciedad, villanía y perdición. En fin, ¡casi siempre, o siempre, son formas camufladas de comunismo ateo! Como argumenta Roger Chartier (1988), las representaciones construyen identidades, posiciones y modos de narrar la historia y siempre están en lucha por la primacía de la producción de la inteligibilidad del mundo.

No sin razón, la defensa de la escuela contra el comunismo y contra la destrucción de los valores de la familia cristiana es uno de los mensajes más fuertes del movimiento que en el Brasil -y ahora en toda América Latina - se autonombra "escuela sin partido". Este movimiento actualiza todas esas tradiciones ya citadas y, con el apoyo de antiguos y nuevos repertorios de acción las movilizan en un intenso ataque a las conquistas democráticas y de las minorías políticas o culturales. Para ese movimiento, que logró reunir en un mismo ejército a católicos y protestantes, todo el que contraría su lectura fundamentalista de la Biblia y el libre curso del mercado es comunista, es "rojo", es una amenaza a la armonía del cuerpo social y como tal debe ser combatido y eliminado. Desde este punto de vista, creo, debe ser entendida la alegría y el júbilo de los electores de Bolsonaro cuando éste señala que es preciso eliminar todo el activismo y expulsar del país o encarcelar a los militantes del Partido de los Trabajadores. Volvemos, de esta forma a los momentos más oscuros de nuestra historia y no solamente de nuestro país, sino de todo el mundo. Y los profesores, sobre todo los que enseñan historia, son blanco de los partidarios de una escuela sin pensamiento crítico.

Pero para nosotros es importante entender los movimientos como el de "escuela sin partido" y su poder sobre la escuela. Creo que, sobre todo, en nuestro país ellos saben que, a pesar de su precariedad, la escuela pública es la más republicana y capilar de nuestras instituciones y que las maestras, con toda la precariedad de su formación y sus condiciones de trabajo, son las personas que pueden ayudar a los niños y a las niñas a vislumbrar que otra vida es posible desde las prácticas escolares de la vida cotidiana. 
La gran meta de los adeptos de la "escuela sin partido" es evitar que quienes luchan por una escuela más democrática e inclusiva tengan acceso, con sus imágenes y acciones, al interior de la escuela. La invención y difusión del término "ideología de género" para sintetizar su aversión por todo aquello que les resulta contrario a la familia nuclear, patriarcal, idealizada y burguesa fue una estrategia simbólica fundamental. En ese sentido poco importa -y ellos saben de esto- si sus representaciones de familia son muy idealizadas. En efecto, una de sus misiones es justamente denunciar la inconformidad de la realidad en relación con los modelos que consideran bíblicos y, por tanto, ajenos a su ortodoxia histórica. Entre tanto, aguardan la venida del Cristo salvador con la certeza de que están cumpliendo su misión en la tierra aun cuando su misión sea segar vidas ajenas.

Este conjunto de elementos —además de los que abordé anteriormente-, entre los cuales ciertamente no he agotado todas las reflexiones posibles, ponen en nuestra agenda como educadores y como historiadores de la educación un conjunto de desafíos.

Un primer desafío es hacer en definitiva una crítica a la educación escolar y sus promesas de liberación del sujeto. Sabemos que ésta no es una novedad, pero aún hoy buena parte de la historia de la educación es la historia de la epopeya iluminista de la institución y muy poco la historia de la destrucción política, cultural, económica y epistemológica traída por la escuela. Del mismo modo, buena parte de nuestra historia de la educación es la historia de la razón, del intelecto, de lo razonable, de lo cognitivo, del conocimiento y del conocer, mientras que es muy poco de la educación de las sensibilidades y de los sentidos y, por ende, de los miedos, las pasiones, los enojos, los odios, las violencias, del aniquilamiento de los otros, es decir, jla educación para la paz, para la integración, para la empatía con los otros, para el encuentro con la diferencia, para el cariño, para el amor! Esto significa, desde el punto de vista de la historia de la educación, una mirada más amplia de lo educativo en la historia y un acercamiento más fuerte a disciplinas como el psicoanálisis y las artes, además de otras con las cuales ya hemos hecho aproximaciones en las últimas décadas.

Pienso que es necesaria una crítica más amplia y cada vez más pública de las memorias, cultivadas y diseminadas por los sujetos de gran éxito escolar y por los medios, sobre la "buena educación" del pasado; esta crítica es absolutamente fundamental y un desafío del cual nosotros no podemos huir. No se puede olvidar que la escuela del pasado inmediato era una escuela mucho más autoritaria, machista, racista y excluyente que la escuela que tenemos hoy. Y también es nuestra tarea como historiadores no dejar a la sociedad olvidarse de ello. A nosotros, como ciudadanos y como historiadores de la educación, nos importa mostrar que la escuela y la educación siempre tuvieron partido, siempre han tomado partido, y que lo que incomoda es que ahora la escuela ha incorporado a otros partidos y no solamente al partido de los blancos, ricos, viriles y cristianos. 
Una historia de la educación de este tipo no es una historia de la escuela. Es una historia de todo aquello que forma, que transforma a los recién llegados al mundo —en los múltiples espacios y tiempos - en este animal complejo capaz de las cosas más elevadas y amorosas del mundo, pero también de las peores villanías y violencias que existen en la Tierra. Ese es el humano y nada que se refiera a su formación debería ser olvidado por la historia de la educación.

Pachuca de Soto, 10 de noviembre de 2018

Nota del autor

El Brasil, un año después: Hoy, cuando hago la revisión del texto presentado en el congreso, ha transcurrido exactamente un año desde que fue presentado en el XV Encuentro Internacional de Historia de la Educación. Es también un momento histórico para nosotros, brasileños demócratas: ayer, 8 de noviembre, el ex presidente Lula da Silva abandonó la prisión, adonde jamás debió ser llevado. ¡Es un momento de fiesta! Pero también es un momento de articulación de las fuerzas demócratas del país para pelear contra el gobierno del presidente Jair Bolsonaro y la catástrofe que ha impuesto al Brasil y su gente. La necropolítica que el gobierno viene practicando ha resultado en la devastación de la naturaleza, en la desorganización de las políticas públicas y en la muerte de la población, sobre todo indígenas, negros, LGBTOI y pobres en general. Luchar contra la aniquilación de la vida, de todas las vidas que habitan nuestro territorio - y en todos los territorios del planeta- es un imperativo ético y político que no podemos olvidar jamás. Esto también es hacer educación y crear las condiciones para que en el futuro la historia de la educación sea necesaria.

\section{Referencias}

Benjamin Walter (1985), "As Teses sobre o Conceito de História", Obras Escolhidas, vol. 1, São Paulo, Brasiliense, pp. 222-232.

Chartier, Roger (1988), A história cultural: entre práticas e representações, DIFEL, Lisboa.

Cunha, Luiz Antônio (1989), Qual universidade?, Cortez, São Paulo.

Faria Filho, Luciano Mendes de (2006), "Dinâmicas de escolarização no Brasil do Século XX: da sala de aula a uma economia política da educação nacional”, Estudos do Século XX, vol. 6, pp. 95-110.

Hamilton, David (1989), Towards a Theory of Schooling, The Falmer Press, East Sussex.

Pessanha, Eurize Caldas y Gatti Jr. Décio (2012), Tempo de cidade, lugar de escola: história, ensino e cultura escola em "escolas exemplare", EDUFU, Uberlândia. 